\title{
Childhood Ovarian Yolk Sac Tumor
}

National Cancer Institute

\section{Source}

National Cancer Institute. Childhood Ovarian Yolk Sac Tumor. NCI Thesaurus. Code C6551.

A yolk sac tumor that arises from the ovary and occurs in children. 